\title{
DE ANTHROPOLOGIE VAN HET NIEUWE TESTAMENT VERGELEKEN MET DE ANTIEKE
}

Het beschrijven van de anthropologie van het Nieuwe Testament brengt zijn eigenaardige moeilijkheden mee. Men moet n.l. beginnen met te vragen: „bestaat er wel zo iets als een anthropologie van het N.T.?" Kan men zeggen, dat het N.T. een leer van de mens geeft? Mij dunkt, wanneer men deze neemt in de strikte zin van het woord, zal gezegd moeten worden, dat men slechts met reserve kan spreken van een anthropologie. Een leer van de mens, van zijn eigenschappen, zijn innerlijk leven, zijn menselijke mogelijkheden, zijn zielsontroeringen, zijn deugden en bekwaamheden geeft het N.T. niet. Men versta dit goed: hier en daar valt er op grond van bepaalde gegevens over enkele van deze menselijkheden wel iets te zeggen, maar het betreft dan gegevens, die eigenlijk altijd in een ander kader thuishoren dan dat der anthropologie. Daarvoor heeft men in het N.T. voor de mens als zodanig, voor al zijn antrhopologisch interessante of niet interessante menselijkheden te weinig belangstelling, omdat de wezenlijke belangstelling daar naar iets anders uitgaat. Zodra men de gegevens van het N.T. tracht te vatten onder anthropocentrisch gerichte termen, kan men soms na moeizaam samenlezen van verspreide, terloops geuite woorden wel iets gevonden menen te hebben, maar men zal in elk geval tot de ontdekking komen, dat alles, wat in het N.T. wezenlijk belangrijk geacht wordt, er precies buitenvalt. 
In dit opzicht is het soms zeer veelzeggend, dat bepaalde woorden en begrippen, die in de gelijktijdige antieke wereld zeer veel gebruikt worden, in het Nieuwe Testament nauwelijks of in het geheel niet voorkomen. En dit welsprekend zwijgen van het N.T. geldt dan vaak o.a. in het bijzonder die woorden en begrippen, die onwillekeurig de mens in het middelpunt stellen. Een ethisch kernwoord is in de oudheid zonder twijfel het woord „,deugd". Philo Alexandrinus bijv. zingt doorlopend een lofzang op de deugden en op deugdzame mensen. De deugden, zo schrijft hij, behouden voor eeuwig haar reine en onvergankelijke natuur'. $\mathrm{Zij} z \mathrm{ijn}$ die onver gankelijkheid waardig ${ }^{2}$. Een goed man is door zijn menszijn verbonden met het sterfelijk geslacht, maar door de deugd met het onsterfelijk geslacht $^{3}$. De ware rijkdom bestaat uit volmaakte deugden en deugdzame daden ${ }^{4}$. Hoeveel mensen weten niet van de mysteriën van de kunst van de zielslandbouw, die de deugd in de ziel zaait en plant en als haar vrucht het zalige leven oogst ${ }^{5}$.

Men ziet, Philo word lyrisch, als hij over de deugd schrijft. Dat ook de Stoa doorlopend dit begrip gebruikt in de beschrijving van het zedelijk gedrag en in de ethische vermaning, is reeds bij oppervlakkige lezing van geschriften als van Seneca en Epictetus duidelijk. Ter illustratie slechts één aanhaling uit Seneca's De vita beata:- -de deugd laat het slechte leven niet toe - de deugd is iets hoogs, verheven en koninklijk, onoverwonnen, onvermoeibaar - (virtus malam vitam non admittit -: altum quiddam est virtus, excelsum et regale, invictum, infatigabile. ${ }^{6}$

$\mathrm{Nu}$ is het alvast merkwaardig, dat het woord „,deugd", waarvan Philo's gesshriften wemelen, uitsluitend voorkomt in zijn breedvoerige allegorische verklaringen van teksten uit het Oude Testament, maar nimmer in die teksten zelf. Het Oude Testament heeft dan eigenlijk ook geen aequivalent voor het Griekse woord aretē en het Jodendom neemt het woord pas dan en daar op, waar het Hellenistisch beïnvloed is. ${ }^{7}$ Philo gebruikt bepaalde teksten uit het $\mathrm{O}$.T. als uitgangspunt voor zijn uitweidingen over de deugd, echter zonder dat die teksten zelf er aanleiding toe geven. Uit de bekende tekst Deut. 30: 5: ,Zie, ik heb u heden voorgesteld het leven en het goede, en de dood en het kwade" maakt hy die gevolgtrekking, dat het goede en de deugd leven betekenen, het kwade en de slechtheid de dood. ${ }^{8}$ Bij Gen. 4:10: ,En God zeide: Wat hebt gij gedaan? Daar is een stem van het bloed uws broeders, dat tot Mij roept van de aardbodem" merkt Philo op, dat eigenlijk Abel leeft en Kaïn dood is : hij, die zich over-

1) Quod deterius potiori insidiari soleat. 77

2) So.ii.258.

3) So.ii. 230.

4) Spec. Leg. II 23

5) Agr. 25

6) De Vita beata $7: 2,3$

3) cf. R. Bultmann, Glauben und Verstehen, 1933. S. 232

8) Fuga inv. 58. 
winnaar waant, is de dood der ziel gestorven, omdat hy uitgesloten werd van der deugd, naar welke te leven tenslotte alleen waade heeft. ${ }^{9}$ De boom des levens wordt door hem geinterpreteerd als de deugd in het algemeen, waaruit de afzonderlijke deugden zijn afgeleid.10 Zo moet Philo met behulp van de allegorie zijn beschouwingen over de deugd uit het O.T. afleiden. Daarmee plaatst hij echter de teksten uit het O.T., die hij daarvoor gebruikt, in een ander gedachtenklimaat over.

Ook vanuit het N.T. zou men slechts geforceerd een lofzang op de deugd kunnen aanheffen. In de evangeliën komt nergens het woord aretē voor, daarbuiten slechts vier maal, waarvan dan nog tweemaal van God gezegd: 1 Pt. 2:9, waar de gemeente geroepen wordt om de grote daden van God te verkondigen. Terecht spreekt de vertaling van het Ned. Bijbelgenootschap hier van ,de grote daden" en niet gelijk de Statenvertaling van ,deugden". In 2 Pt. 1:3 wordt van God gezegd, dat Hij ons geroepen heeft door zijn heerlijkheid en macht idia doxē kai aretē. Slechts op twee plaatsen wordt dus van de deugd gesproken in verband met de mens, Phil. 4:8: . . . al wat deugd heet en lof verdient, bedenkt dat ... en $2 \mathrm{Pt}$. $1: 5:$. . . schraagt met betoon van alle ijver door uw geloof de deugd, door de deugd de kennis ... Dat is alles wat over aretē in het Nieuwe Testament te vinden is. En het is toch eigenlijk geen wonder, dat dit woord daar weinig te vinden is. Het veelvuldig gebruik van arete is meestal een teken, dat de ethiek anthropocentrisch gericht is. Immers in dat woord klinkt onwillekeurig iets door van menselijke voortreffelijkheid, van menselijke verdienste ook, op zijn minst van grote aandacht voor menselijke prestaties. En dat alles ontbreekt nu eenmaal in het N.T.

Vandaar bijv. dat een van de vier Stoïcijnse hoofddeugden (sophia, andreia, soophrosune, dikaiosunē), de dapperheid, de andreia, volstrekt niet in het N.T. genoemd wordt. Pas bij Hermas duikt het woord weer op. Bij Philo, Seneca, Epictetus komt het zeer veel voor. Weer, die verhouding is niet verwonderlijk. Terecht, zegt Preisker : ${ }^{11}$ "Tapferkeit redet von einer Haltung des Menschen, die ihn nur in Beziehung zu sich selbst und zu einem anderen Menschen bringt; sie redet davon, dasz der Mensch zu siegender Kraft, zu vollem Selbst- und Herrscherbewusztsein gelangt ist, kurz, sie redet von der menschlichen Grösze, geht vom Menschen aus."

Wel is er natuurlijk ook in het Nieuwe Testament, in al zijn delen, sprake van strijd, zelfs, anthropocentrisch geoordeeld, van heldhaftige strijd, van dapperheid, van ongelooflijke moed. Maar ook waar die vanzelfsprekend getoond wordt, zal men die houding toch nooit uitdrukken in termen van de Stoïcijnse deugdenleer, omdat men ook in die situaties, waarin gestreden wordt en waarin dapperheid getoond wordt, nooit met zijn aandacht gericht staat naar de mens, maar naar de heilsgeschiedenis.

9) Det pot

10) Leg. All. I. 59

11) Herbert Preisker, Das Ethos des Urchristentums. 1949. 
Daarom staan in het N.T. daar, waar de Stoa van andreia zou spreken, die termen, die nadrukkelijk verwijzen naar het heilsgebeuren en daarom nooit bij de mens blijven staan, gelijk bijv.: het kruis op zich nemen, het gekruisigd worden, het sterven, en opstaan met Christus, het volharden tot het einde, de hupomone en de dokimē in de thlipseis, de verdrukkingen, die er immers op wijzen, dat men in de eschatologische wendingen van de tijd leeft. En de reden, waarom men in het N.T. weet altijd vol goede moed te mogen zijn - het tharrein kom daar herhaaldelijk voor - is niet het rotsvaste vertrouwen op iets in zichzelf, maar de volstrekteverzekerdheid van Gods heilsoeconomie, die in Christus, zijn verschijning, zijn lijden, sterven, opstaan reeds nu vast verankerd is en die eens het werk, dat begonnen is, ten einde toe zal voortzetten tot de dag van Christus Jezus (Phil. 1:6).

Zo is tot in het woordgebruik toe aan te tonen, dat het N.T. niet anthropocentrisch gericht is. Daarom is het ook niet zo eenvoudig, direct, in samenhang, uit het N.T. af te lezen, wat daar aangaande de mens verkondigd en geleerd wordt. Dat men in de evangeliën, in Jezus' verkondiging vaak moeizaam teksten, uitspraken moet bijeen zoeken, om nu eens te zeggen, hoe Hij oordeelde over des mensen innerlijk leven, zijn zonde, over zijn lichaam, zijn ziel, zijn geeest, mag bekend genoeg heten. Wanneer men echter zou zeggen, dat wij, wat dat betreft, er in de brieven van Paulus veel beter voorstaan, dan is dat slechts in bepaalde zin waar. Zeker, Paulus laat zich in bepaald verband veel uitvoeriger, opzettelijker, concreter uit over de mens, de oude en de nieuwe mens, over het vlees en de geest, over lichaam en ziel, en toch, wanneer men zulke uitspraken weer niet al te haastig uit hun verband licht en isoleert, dan zal blijken, dat ook hij dan niet spreekt vanuit een anthropologisch interesse of bijv. om een mens zielkundig in dit moeilijke leven de weg te wijzen, te berispen of te bemoedigen, maar uitsluitend om te verkondigen de totaal nieuwe situatie van mens en wereld, sinds God, toen de volheid des tyds gekomen was, zijn Zoon heeft uitgezonden (Gal. 4:4). Stelt men de vraag, of Paulus dichotomisch dan wel trichotomisch aangaande de mens leert, hem in tweeën of in drieën gedeeld denkt, dan pleit allerlei voor het eerste, maar dan klinkt een enkele tekst toch sterk Aristotelisch-trichotomisch, waar het geheel van de mens wordt samengevat als geest, ziel en lichaam. Maar als men bemerkt, in welk verband Paulus deze trichotomie gebruikt, blijkt zonneklaar, dat hij ook dan niet bepaald allereerst vervuld is van de zorg om nu eens anthropologisch scherp te onderscheiden en zijn lezers in hun kennis aangaande de mens te verrijken. Hij schrijft aan de Thessalonicensen: En hij, de God des vredes, heilige u geheel en al, en geheel uw geest, ziel en lichaam, to pneuma kai hë psyche kai to sōma, moge by de komst van onzen Heer Jezus Christus blijken in allen dele onberispelijk bewaard te zijn. Die u roept is getrouw; Hij zal het ook doen (1 Thess. $5: 23$ ). Hoe snel verdwijnt de anthropologie weer uit het gezichtsveld. Hoe dwaas zou iemand doen, die bij deze uitspraak alle nadruk zou laten 
vallen op het anthropologische detail en de theologie, de christologie, de soteriologie van dit woord van Paulus zou willen bagatelliseren.

Om zich het kenmerkende van het N.T. op dit punt helder voor ogen te stellen, behoeft men eigenlijk niets anders te doen dan zich een tijdlang te verdiepen in geschriften van de kant van de Stoa. Men zal spoedig genoeg bemerken, dat bij het onderscheid, dat dan aan de dag komt, de verschillen tussen de afzonderlijke geschriften van het N.T. welhaast wegvallen, in elk geval bij hun gemeenschappelijk front tegenover de niet-Christelijke schrijvers nauw elijks meer ter zake doen. Veelzeggend zijn bijv. alleen reeds de titels van de belangrijkste geschriften van een man als Seneca. Die schrijft brieven of opstellen de vita beata, de tranquillitate animi, de constantia sapientis, de otio, de brevitate vitae, de ira, de morte .Claudii. Men merkt het, ook als men de inhoud nauwelijks of niet zou kennen, daar komt de mens aan bod, zijn geluk, zijn gemoedsrust, zijn kracht als wijze, zijn gemoedsbewegingen, daar hoort men, wat een mens, gegeven zijn aard, zijn aanleg, zijn moeilikheden en zijn innerlijke strijd, zijn drukte en zijn genietingen, nu moet doen, hoe hij zich kan ontwikkelen en zich leren beheersen. En als men zou tegenwerpen, dat deze zelfde Seneca toch ook de providentia divina, over de goddelijke voorzienigheid geschreven heeft, dan blijkt bij kennismaking met de inhoud spoedig genoeg, dat ook in dat geschrift de vraag op de voorgrond staat, hoe de mens het vanuit de onbewogenheid en de onaantastbaarheid van de wijze onder alle omstandigheden met de wisselvalligheden van deze providentia divina klaarspeelt. - Wil men de tegenstelling scherp stellen, dan zou men hem misschien aldus kunnen formuleren: bij Seneca wordt eigenlijk steeds over en vanuit de mens gesproken en slechts terloops over de godheid, in het N.T. is primair steeds aan de orde wat God gedaan heeft, doet en zal doen in Christus en wordt alleen, voor zover het in dat verband van gewicht is, over de mens gesproken.

Het is nu wel duidelijk, dat men in het N.T. eigenlijk niet afzonderlijk over de anthropologie als een zelfstandig geheel kan spreken en in geen geval goed in het vizier kan krijgen, waarop het in deze anthropologie aankomt, als men haar los zou maken van de theologie en de christologie. De mens is in het N.T. daardoor gekarakteriseerd, dat hij aangesproken wordt door God, de Schepper van hemel en aarde, de Heilige, de zalige en enige Heerser, de Koning der Koningen en de Heer der Heren, die alleen onsterfelijkheid heeft en een ontoegankelijk licht bewoont, dien geen der mensen gezien heeft of zlen kan, wien alleen eer en eeuwige kracht toekomt (1 Tim. 6:15vv.). Deze God heeft recht op de mens, de gehele mens. Van Hem is de mens afhankelijk, volstrekt afhankelijk, jegerss Hem is de mens verantwoordelijk met al zijn denken, spreken, willen. De ganse mens met het lichaam en ziel, of hoe men hem verder anthropologisch ook nader wil aanduiden, wordt opgeroepen om Gods gebod te gehoorzamen. 
Zodra de mens beseft, dat hij als schepsel, als nietig, vergankelijk, sterfelijk, zondig wezen staat voor dien Heer der Heren, die alleen onsterfelijkheid heeft, die alleen heilig is, weet hij ook, dat er van nature een diepe kloof gaapt tussen God en mens, een kloof, die alleen van Gods zijde overbrugd kan worden, dat hij met zijn gehele persoon, met zijn lichaam, maar ook met zijn ziel, ook met zijn menselijke geest, zondig is voor God. En die kloof is overbrugd, doordat niet slechts Gods oordeel in Christus over de mens gaat en zal gaan, maar ook in Christus vergeving en verzoening door God in zijn genade is gegeven. Daarin alleen ligt de bevrijding, de verlossing voor de zondige mens.

En weer kan de eenheid van het N.T. duidelijk gedemonstreerd worden aan het feit, dat het gehele N.T. op dit funt een gesloten front vormt tegenover de anthropologie, die bij vele Griekse of Romeinse schrijvers aan de dag komt. Ik heb er nadruk op gelegd, dat de mens als geheel in zijn ganse persoon, hoe dan ook verder anthropologisch beschreven, verantwoordelijk, daarom van nature zondig, voor God staat. Hier is het onderscheid met niet-Christelijke schrijvers, Platonische of Stoïcijnse, onmiddellijk duidelijk. Kortweg gezegd is het dit: in het N.T. wordt, ook anthropologisch, de enige, werkelijk belangrijke, scheidingslijn getrokken naar het heilsgebeuren in Christus, naar het woord van Paulus in de brief aan de Epheziërs (Eph. 5:8): ,gij waart vroeger duisternis, maar thans zijt gij licht in den Heer"; buiten het N.T. acht men anthropologisch scheidingslijnen binnen het leven van de mens zoals hij is, de natuurlijke mens, zeer belangrijk, en wordt op het scherper accentueren van die scheidingslijnen door de mens telkens een beroep gedaan.

In het N.T. kent men bijv. niet de tegenstelling tussen het lichamelijke, zinnelijke, verachtelijke, het lagere ter ener zijde en het hogere, het geestelijke ter anderer zijde. Als Eichrodt in zijn boekje over „Das Menschenverständnis des Alten Testaments" met het oog op het O.T. zegt: „Hier kann man nicht wie es der Idealismus verschiedenster Prägung tut, das natürlich-leibliche Sein als minderwertig und gleichgültig dem allein wertvollen, in sich gesicherten und unantastbaren geistigen Sein gegenüberstellen und als unwichtig für die Verwirklichung des Lebenszieles bezeichnen". S.33., dan geldt dit niet minder van de beoordeling van de mens in het N.T. En men gevoelt onmiddellijk het karakteristieke op dit punt van de gehele bijbelse verkondiging, wanneer men er enkele kenmerkende uitspraken van niet-Christelijke schrijvers naast stelt. In de Phaedo zegt Socrates: „Bedenk, dat, wanneer ziel en lichaam bijeen zijn, de natuur aan het laatste (het lichaam) beveelt te dienen en te gehoorzamen, maar aan de eerste (de ziel) te heersen en te gebieden; en wie van beide meent gij, dat ook volgens die beschouwing meer of minder gelijk is aan het goddellijke of aan het sterfelijke? Of meent gij niet, dat het goddelijke van nature bestemd is om te heersen en te bevelen en het sterfelijke 
om te gehoorzamen en te dienen? - Zeker - Op welk van beide gelijkt de ziel dan? - Ongetwijfeld gelijkt de ziel op het goddelijke, het lichaam op het sterfelijke. - Ga dan eens na, Kebes, hernam hij, of uit al het gezegde dit voor ons volgt, dat de ziel zeer gelijk is aan het goddelijke, onsterfelijke, denkbare, eenvoudige, onoplosbare en zich zelf altijd gelijk blijvende, het lichaam daarentegen aan het menselijke, sterfelijke, alleen met de zintuigen waarneembare, veelgestaltige, oplosbare en zichzelf nooit gelijk blijvende"12.

In zulk een citaat, waarvan de grondgedachten waarlijk niet alleen de oudheid op allerlei wijze diepgaand hebben beïnvloed, maar via velerlei soorten van idealisme tot op heden hebben doorgewerkt, bemerkt men onmiddellijk een zeer bijzonder klimaat van gedachten, dat grondig verschilt van dat van het Nieuwe Testament. Hier betekent de mens iets, hier is hij veel waard in zichzelf, hier is geen sprake van een afgronddiepe kloof tussen Schepper en schepsel, tussen de heilige God en de zondige mens, neen, hier loopt een ongebroken lijn van de mens naar het goddelijke, een lijn, die dan ook na het sterven eenvoudig doorloopt. En het komt er slechts op aan, dat een mens in zijn denken en in zijn doen trouw blijft aan dat hogere in hem, de ziel, die zeer gelijk is aan het goddelijke en onsterfelijke. Dat kost natuurlijk strijd, maar door eigen inspanning, door zelfbeheersing, door zichzelf te ontwikkelen in de goede richting kan een mens het onvergankelijke, goddelijke leven vinden. Het komt er slechts op aan, dat de zelfgenoegzame, autonome mens in overeenstemming met de natuur leeft. Dit laatste acht Seneca een punt, ten aanzien waarvan alle Stoïci het eens zijn. In zijn geschrift, „De vita beata” vindt hij het de eigenlijke, rechte wijsheid, als men van de natuur niet afdwaalt en zich vormt naar haar wet en voorbeeld; gelukkig is daarom een leven, wanneer het in overeenstemming met de natuur is ( $a b$ illa non deerrare et ad illius legem exemplumque formari sapientia est: beata est ergo vita conveniens naturae suae. ${ }^{13}$ Als een mens dit leven niet bereikt, dan komt dat hieruit voort, dat hij zich door het lichamelijke, het zinnengenot, de wellust laat overheersen, doordat ,non ipsi voluptatem, sed ipsos voluptas habet". ${ }^{14}$

In deze gedachtenwereld hoort toch niet thuis het psalmwoord, dat Paulus in Rom. 3 met instemming aanhaalt: Niemand is rechtvaardig, ook niet één, er is niemand, die verstandig is, niemand, die God ernstig zoekt, allen zijn afgeweken, tezamen zijn zij onnut geworden; er is niemand, die doet, wat goed is, zelfs niet éér. Deze anthropologie valt geheel onder het oordeel van dat woord uit die eerste brief van Johannes: „Indien wij zeggen, dat wij geen zonde hebben, misleiden wij onszelf en de waarheid is in ons niet" (1 Joh. 1:8). Inderdaad, vanuit het N.T. geoordeeld, moet het zelfmisleiding heten, wanneer Seneca kan spreken van een mens, die zich

12) Phaedo, 79E-80 B.

13) SENECA, De beata vita. 3:3.

16) id. ibid. 14:1. 
verheugt in zijn deugd (virtute laetus), van een onoverwinnelijke kracht der ziel (invicta vis animi $)^{15}$, van een mens, die vol vertrouwen in zichzelf is zelf zijn leven vormend (fidens animo - artifex vitae) ${ }^{16}$, die alles kan doen, wat hij zichzelf opgeeft (omnia faciet ex imperio suo), wiens hoogste goed is de animi concordia, ${ }^{17}$, die als een vir erectus, een opgericht, recht opstaand mens ${ }^{18}$ door het leven kan gaan.

Het spreekt vanzelf, dat dit grondonderscheid in velerlei opzicht belangrijke consequenties heeft. Om er een te noemen, die zich misschien aanvankelijk het best negatief laat formuleren: elke gedachte van een geleidelijke zelfontwikkeling tot wat men dan pleegt te noemen een hoogstaande persoonlikheid ontbreekt in het N.T. „Höchstes Glück der Erdenkinder sei nur die Persönlichkeit" dicht Goethe in zijn Buch Suleika. Zulk een hoogst geluk word in het N.T. volstrekt niet gezocht en ook niet mogelijk geacht. En weer: in de gelijktijdige antieke wereld komt men deze gedachte van de zelfontplooiing veelvuldig tegen. Geen wonder! Immers zelfontplooiing, karaktervorming wordt overal daar mogelijk geacht, waar voor zulk een innerlijk proces inderdaad van dat zelf kan worden uitgegaan, waar in de mens iets is, zijn wil, zijn geest, waarbij men kan aanknopen, waar hij in zichzelf een centrum heeft. ${ }^{19}$ Dan heeft de autonome mens in zichzelf de mogelijkheid om zich tot een persoonlijkheid te vormen. Maar wanneer de mens in zijn geheel met lichaam en ziel als zondig staat voor de heilige God en in allen dele afhankelijk is van het heil van God, van de heiliging door Gods Geest, die een andere is dan de menselijke geest, dan kan men natuurlijk wel spreken van een nieuwe mens tegenover de oude mens - het is bekend genoeg dat het N.T. dat veelvuldig doet doch dan vormt de nieuwe mens zich niet geleidelijk uit de oude, maar is het de nieuwe mers, die naar het woord uit de brief aan de Epheziërs naar de wil Gods geschapen is in waarachtige gerechtigheid en heiligheid. ton kainon anthrōpon ton kata theon ktisthenta en dikaiosonē kai hosiotēti tès alētheias (Eph. 4:24).

Dat gaat dwars in tegen het ideaal van de harmonisch gevormde persoonlijkheid. En wederom geldt m.i. voor het N.T. geheel wat Eichrodt van het Oude zegt: "Dasz hier kein Raum ist für eine in sich geschlossene und harmonisch abgerundete Leber sgestalt, für die Formung der Persönlichkeit zum Kunstwerk nach den Forderungen des Ideals des kalon kagathon liegt vor der Hand. Man hat mit Recht darauf aufmerksam gemacht, dasz das Alte Testament keine Heroen und Heiligen kenrt. Zu stark ist das ständige Gefragtsein und In Frage-gestellt-sein empfunden als dasz es zum Vertrauen auf ein in sich ruhendes Idealbild der menschlichen Persönlichkeit kommen könnte-20.

15) id ibid. $4: 2$

16) id. ibid. $8: 3$.

17) id. ibid, $8: 6$.

18) id. De Const. sap. 9:3

19) R. Bultmann, Jesus. z.j. S. 198.

20) Das Mensch verstandnis des Alten Testaments. S. 25. 
En dat hier O. en N.T. gezamentlijk een front vormen laat zich concreet aan een voorbeeld gemakkelijk illustreren. Het woord teleios komt in de evangeliën slechts tweemaal voor, en dan alleen bij Mt. op zeer bekende plaatsen: eerst aan het slot van het eerste hoofdstuk van de Bergrede, Mt. 5:48: Gij zult volmaakt zijn, gelijk uw hemelse Vader volmaakt is; de tweede maal in het gesprek van Jezus met de rijke jongeling: Indien gij volmaakt wilt zijn, ga heen, verkoop uw bezit en geef het aan de armen, en gij zult een schat in de hemelen hebben, en kom hier en volg Mij (Mat. 19:21). Volmaakt worden, volmaakt zijn - men zou er bij kunnen denken aan die geleidelijke zelfvervolmaking, dat eindresultaat van een ontwikkeling van eigen persoonlijkheid, zodat de wijze tenslotte gelijk Seneca van zichzelf meent te kunnen getuigen bonam me conscientiam amasse, bona studia, een goed geweten en een edel streven te hebben bemind, en die dan ook zeker mag zijn qui haec facere proponet, volet, temptabit, ad deos iter faciet, wie dit ran plan is, te doen, te willen, te trachten, diens weg zal naar de goden gaan. ${ }^{21}$ Dat doet oppervlakkig misschien enigszins denken aan de teleios - teksten uit Mt. Maar ook hier dient de klankovereenkomst niet te bedriegen. In Mt. 5:48 en 19:21 is geen sprake van het Griekse begrip der volmaaktheid, maar dat teleios is hier Semietisch getint. Het betekent: ,volledig", ,geheel" gelijk tamîm en sjalèm. In Mt. 19:21 komt die zin het duidelijkst aan de dag. De rijke jongeling heeft reeds veel gedaan, de geboden heeft hij vanaf zijn jeugd opgevolgd, maar voor het verkrijgen van het eeur ige leven, voor het volgen van Jezus, zal hij het volstrekte offer moeten brengen. Dan mag hij in geen enkel opzicht meer weifelen. Dan moet hij door een besliste daad tonen, dat hij in zijn keuze voor Jezus „,een man uit één stuk" is.

$W_{i j}$ zullen dan ook, om het juiste zicht te krijgen op het teleios van het Evangelie, m.i. veel meer naar de Semietische dan naar de GrieksRomeinse kant moeten kijken. Misschien zou het voor het juiste begrip van dit woord bijv. ook dienstig kunnen zijn om te gaan letten op het gebruik van de woorden tamim en tōm in het Manual of Discipline, de gemeenteregel, die gevonden is onder de Dode-Zee-rollen. Het is opvallend, hoe vaak deze woorden hier gebruikt worden. Reeds in de aanvang wordt gezegd, dat de regel gegeven is, opdat de leden zich zouden gedragen als volmaakte mensen voor God volgens alles wat geopenbaard is aan hun plechtige vergaderingen (letterlijk vergaderingen van getuigenissen, 1:8 v. cf. $3: 3,9 ; 10: 21)$. Het komt er op aan om volmaakt tamim te wandelen in al Gods wegen (2:2); ieder lid moet vasthouden aan de volmaaktheid van zijn weg, de tōm darko (5:24 cf. 11:12), moet wandeler in een volmaakte weg, betamim derek, $(8: 10$, cf. 8:18, 21, 25; 9:5, 6, 8.9). Dit alles moge aanvankelijk lichtelijk moralistisch wettisch klinken, aan het slot van het geschrift blijkt het duidelijk, dat het allerminst zo bedoeld is. En hoever men ook in dit geschrift verwijderd is van elke gedachte aan de zelfvervolmaking van de autonome mens blijkt, wanneer op de laatste bladzijde van het

21) De Vita beata-20:5 
geschrift zeer persoonlijk beleden word: Mijn rechtvaardiging behoort aan God; de volmaaktheid van mijn weg en de rechtheid van mijn hart zijn in $\mathrm{Zijn}$ hand $(11: 12)$. De gerechtigheid behoort aan God en het is uit zijn hand dat de volmaaktheid van de weg voortkomt, umijjado tom hadderek $(11: 10 \mathrm{v}$.$) . En in de zegen, die het geschrift besluit, wordt tot God ge-$ roepen : zonder $U$ is de weg niet volmaakt en zonder $U w$ welbehagen gebeurt er niets (11:17). Alles, ook het volmaakte gedrag van de mens, rust in het welbehagen, de racōn van God. Daarmede is ook aan dit veelvuldig spreken over tamim en tōm elke menselijke zelfverheffing, elke zelfbewustheid van de autonome mens ontnomen.

Ik noem nog een andere consequentie, die m.i. uit het grondonderscheid in de anthropologie voortvloeit en met het voorgaande min of meer samehangt. Daar is in het N.T. sprake van een solidariteit tussen mensen juist in hun zondigheid voor de heilige God, in hun algehele afhankelijkheid voor hun heil van het heilsgebeuren, dat God is begonnen en zal voltooien in Christus, in de mogelijkheid tot vernieuwing en heiliging alleen door Gods Geest, die zelf deel uitmaakt en garantie is van het heil van de eindstrijd, aparchē, eersteling, arrabön, onderpand. Weer ziet men misschien het bijzondere van het Evangelie in zijn positiviteit, wanneer men een gelijktijdige antieke gedachtenwereld en haar uitlopers in latere tijd tot op heden toe daarmee vergelijkt. Er wordt soms een scherpe scheidingslijn getrokken, tussen enkelen als de beschaafden, de deugdzamen, de braven, de wijzen, en de anderen, de grote menigte, de schare als de onbeschaafden, als het gewone, het mindere, het onontwikkelde volk. Waar komt die scheiding vandaan? M.i. kan die alleen daar opkomen, waar men de scheiding binnen de mens, tussen lichaam en geest, zeer ernstig neemt, ja als fundamenteel beschouwt, waar men met de Phaedo de ziel gelijk acht aan het goddelijke. Dan heeft een zekere aristocratie van de geest een kans, die in het N.T. geen voet aan de grond krijgt. Dan komt men vanzelf tot een zekere minachting van de schare, het vulgus, het plebs. Dan kan men zich, zoals Socrates in de Phaedo, er op laten voorstaan, dat men niet spreekt zoals de grote hoop spreekt hōs phasin oi polloi anthrōpoi ${ }^{22}$ dan spreekt het vanzelf, dat het volgens diezelfde Socrates slechts enkelen geoorloofd is tot het geslacht der goden te komer, namelijk aan hen, die de philosophie beoefend hebben en daarom volkomen rein zijn. Daar komen de polloi, die slaaf zijn van de zinnelijke begeerten, natuurlijk niet aan toe. ${ }^{23}$ Seneca waarschuwt zijn broer Gallio, ons uit het N.T. welbekend, in de inleiding van zijn geschrift De vita beata dat hij deze, wanneer het om het geluk des levens gaat, niet mag voorhouden, als bij stemmingen in de senaat; aan deze kant schijnt de meerderheid te staan. Des te erger immers, als de meerderheid aan een bepaalde zijde staat. „Het staat met de mensheid niet zo goed, dat het betere aan de meerderheid bevalt, integendeel een grote menigte is het bewijs van het slechtste". (Non tam bene cum

22) Phaedo. $80 \mathrm{D}$.

23) Phaedo. $82 \mathrm{C}$. 
rebus humanis agitur, ut meliora pluribus placeant: argumentum pessimi turba est ).

Het vulgus is wel de allerslechtste vertolker der waarheid (vulgus veritatis pessimus interpres). En zeker Seneca erkent ten volle - hij heeft waarschijnlijk onder Nero overvloedig gelegenheid gehad om tot die ontdekking te komen - dat men vulgus tegenkomt onder de lieden met kronen zogoed als onder die met een chlamys, onder de coronati zogoed als onder chlamydati, maar Seneca wanhoopt er toch niet aan, dat men het vulgus er uit zal kunnen kennen: de geest vinde des geestes waarde (animi bonum animus inveniat. ${ }^{24}$ En hoe scherp hij de tegenstelling tussen de wijze en het vulgus ziet, blijkt wel, als hij in zijn geschrift „De constantia sapientis" van de wijze zegt: Hij gaat niet dezelfde weg als het volk, maar zoals de sterren een baan lopen, die tegen de aarde ingaat, zo gaat hij dwars tegen de mening van allen in (non it qua populus, sed ut sidera contrarium mundo iter intendunt, ita hic adversus opiniones omnium vadit. ${ }^{25}$

Het behoeft wel nauweliks betoog, dat een dergelijke geringschatting van de schare in allerlei toonaarden door de eeuwen heen klinkt. Laat ik ter illustratie met één voorbeeld mogen volstaan; Goethe zegt op 12 Febr. 1829 tot Eckermann: Alles Grosze und Gescheite existiert in der Minorität . . . Es ist nie daran zu denken, dasz die Vernunft popular werde. Leidenschaften und Gefühle mögen popular werden, aber die Vernunft wird immer nur ein Bezits einzelner Vorzüglicher sein". Enkele voortreffelijken - daarvan kan men alleen spreken, als men in de mens iets kostbaars ziet, gelijk hier de Vernunft, de rede, dat wat enkelen bewaren, ontwikkelen, ontplooier, de grote schare niet.

Zulk een aristocratische minachting van de schare vanuit het besef van eigen diep geestelijk leven is in het N.T. onmogelijk. In het N.T. heeft schare, menigte een geheel andere klank. Daarbij zijn allen ingesloten. Die schare kan zorder uitzondering alleen leven uit wat God schenkt, uit de barmhartigheid Gods.

Het is begrijpelijk, dat een van de oudste bestrijders van het Christendom, Celsus, zich eraan geërgerd heeft, dat het Evangelie al die tegenstellingen, die in de antieke wereld zo belangrijk geoordeeld werder, hard. nekkig bagatelliseert, ja ze zelfs omkeert. Het is alsof het Evangelie zegt: „niemand, die beschaafd is, kome naderbij, geen wijze, geen verstandige, want dat wordt bij ons als een kwaad gerekend; maar als iemand ongeleerd, onverstandig, onbeschaafd, een kind is, laat hij dan vrijmoedig komen."26 „Is het niet ergerlijk, dat het Christendom wolbewerkers, schoenmakers en vollers opneemr, kortom de alleronbeschaafdste en allerboerste lieder. ${ }^{27}$, dat door die Christenen verkondigd wordt, dat het Koninkrijk

24) De vita beata. 2:2.

25) ibid. 14:4.

29) Contra Celsum iii. 44.

27) id. iii. 55 . 
Gods zal opnemen alwie een zondaar, alwie onverstandig, alwie onnozel en om het eenvoudigweg te zeggen: al wie door een boze demon bezeten is?" Iedere andere religie neemt alleen fatsoenlijke, beschaafde lieden op, op wie niets valt aan te merken. In het Christendom lijkt God wel een roverhoofdman, die bij voorkeur booswichten om zich heen verzamelt. ${ }^{28}$

Dat is een protest vanuit een andere anthropologie tegen het N.T., vanuit de ergernis, dat nu plotseling die hele gewichtige tegenstelling tussen voortreffelijke, zedelijk hoogstaande, verstandige, wijze lieden en de schare terzijde geschoven wordt als in wezen er niet toe doende. En misschien intuitief heeft Celsus begrepen, dat het in laatste instantie hier ging om een andere God, de God, die in souvereine genade ook eenvoudigen en zondaars om zich heen verzamelt, niet de God, die de mens vanuit zijn eigen hoogheid van geest wel kan vinden en benaderen, omdat hij er immers in diepste wezen al mee verwant is, zodat hij eigenlijk daarom niets anders te doen heeft dan in overeenstemming met de natuur te leven, al moet helaas toegegeven worden, dat slechts enkelen, een uitgelezen gezelschap, het zover brengen. 